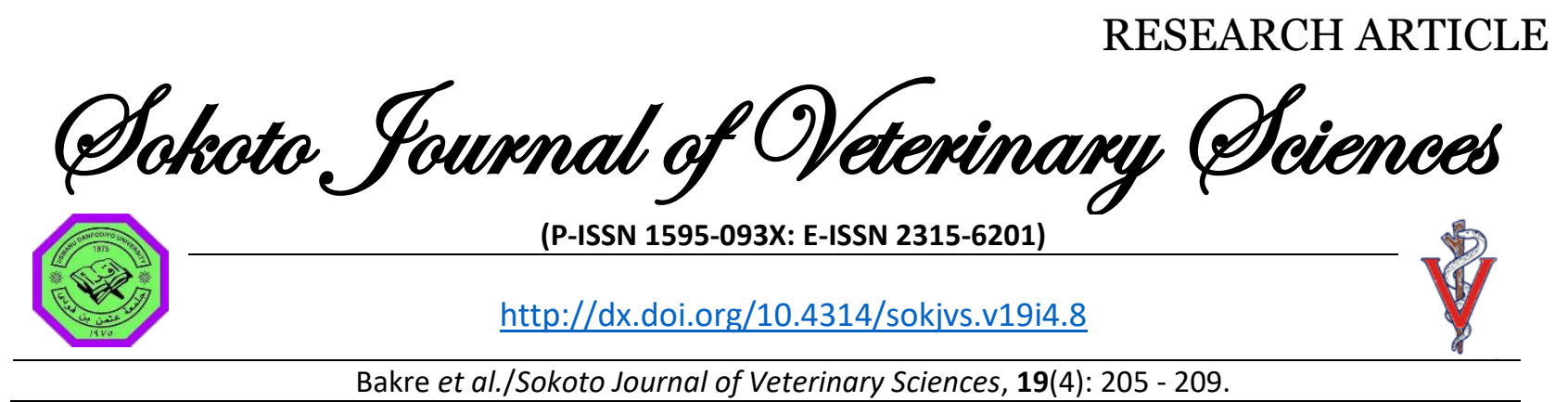

\title{
Seroprevalence of Mycoplasma gallisepticum in apparently healthy layer chickens in commercial farms in Ibadan
}

\author{
AA Bakre*, OR Anifowose \& MA Adegbenro \\ Department of Veterinary Medicine, University of Ibadan, Nigeria
}

*Correspondence: Tel.: +234 8034267054; E-mail: bakreadetolase@gmail.com

\begin{abstract}
Copyright: (c) 2021 Bakre et al. This is an open-access article published under the terms of the Creative Commons Attribution License which permits unrestricted use, distribution, and reproduction in any medium, provided the original author and source are credited.
\end{abstract}

Publication History: Received: 22-06-2021

Revised: 01-09-2021

Accepted: 07-09-2021

Keywords: Antibodies, Seroprevalence, Mycoplasma gallisepticum, Layer chicken, Poultry production

\begin{abstract}
Mycoplasma gallisepticum (MG) is a common poultry infection that causes chronic respiratory disease in chickens and turkeys, resulting in significant financial losses for poultry farmers and affecting the entire country. The primary goal of this study was to establish the seroprevalence of Mycoplasma gallisepticum in commercial layer birds in several local government in Ibadan namely; Afijio, Akinyele, Lagelu, Ido, Egbeda, Ona ara and Ibadan South west, between March and July, 2021. A total of 140 blood samples were obtained at random from commercial layer chickens (ISA brown) of various ages and flock sizes. The presence of antibodies against MG was detected using an indirect enzyme linked immunosorbent test (iELISA). Overall prevalence of $74.3 \%$ was recorded during this study with Deborah farm having the highest MG prevalence of $85 \%$, Agboola, $80 \%$, Brian, Betty and Cornerstone had $75 \%$, Rehoboth had $70 \%$ and Abol farm had the lowest prevalence of $60 \%$. The highest seroprevalence of $M G$ antibody was $85 \%$ in 18 21 weeks, followed by $80 \%$ in $22-25$ weeks, and lowest with $60 \%$ in $8-11$ weeks. In the farm chosen, there was no significant change in relative flock size at $p<0.05$. Moreover, because the disease is transmitted vertically, these findings suggest that commercial layers in Ibadan should be frequently examined for MG infection and carrier birds should be culled. Efforts should be focused on educating poultry producers on how to effectively control MG in layer farms in Nigeria through proper management and the use of appropriate preventive or therapeutic methods.
\end{abstract}

\section{Introduction}

Nigeria's animal business relies heavily on poultry farming (Buim et al., 2009). It's a great way to get a lot of animal protein. Poultry meat is widely accepted around the world due to its lack of religious prejudice. Mycoplasmosis is still one of the most serious health issues impacting poultry in Nigeria (Ahmad et al., 2015). The productivity of the commercial exotic and local breeds are hampered by the disease, which results in severe losses for the country (Silva et al., 2008). Mycoplasma synovae, Mycoplasma meleagridis, Mycoplasma gallisepticum, and Mycoplasma iowae are four pathogenic organisms that cause mycoplasmosis (Hossain et al., 2007). Gallinaceous and non-gallinaceous bird species are 
infected with Mycoplasma gallisepticum which is the most virulent and commercially significant mycoplasma infection (Osman et al., 2009). In meattype birds, this bacteria manifests as chronic respiratory disease in chickens and infectious sinusitis in turkeys (Osman et al., 2009). Mycoplasma gallisepticum is one of the aetiological agents in multifactorial illness complex, along with Haemophillus paragallinarum and other bacteria (Ley and Yonder, 1997). Reduced egg production in chickens, turkeys, and other avian species is one of the clinical indications of MG infection (Ahmad et al., 2008). Mycoplasma gallisepticum infection also reduces feed efficiency, resulting in the production of poor carcass quality and unsatisfactory egg production in layers. The disease has spread all over the world. Clinical symptoms alone are insufficient to diagnose Mycoplasma gallisepticum. Serology and positive culture methods are frequently used. ELISA is the most effective serological test for detecting organisms in the environment quickly (Ahmed al., 2015). Mycoplasma gallisepticum is mostly controlled through vaccine, which is limited in other countries and unavailable in Nigeria despite the disease's severity. The main methods of eradication are tests and slaughter policies. Because of the growth of multiage complexes in the commercial layer industry, this policy appears to be untenable (Mera and Mudashir, 2019). The diagnosis and treatment of chronic respiratory disease in chicken have garnered attention due to its economic implications. The goal of this study is to assess the seroprevalence of Mycoplasma gallisepticum infection in chicken so that effective control measures may be implemented.

\section{Materials and Methods}

\section{Study area}

This study was conducted in seven selected local governments (Afijio, Akinyele, Lagelu, Ido, Egbeda, Ona ara, Ibadan South west) out of the total eleven local governments of Ibadan as shown in Figure 1. Local government areas are purposively selected for this study based on availability of farm and willingness of farm owner to allow samples to be collected from chicken. Ibadan is a capital city of Oyo state located on seven hills (elevation of 700 feet, about 100 miles from the Atlantic coast. It is the most populous city in Oyo state lies between latitude $7^{\circ} 23^{\prime}$ and $9^{\circ} 25^{\prime} \mathrm{N}$ and longitude $3^{\circ} 55^{\prime}$ and $52^{\circ} 50^{\prime} \mathrm{E}$. Ibadan has a radius of 12 kilometers, with Mapo hall as its focal point. Ibadan has a tropical climate that is both wet and dry. The wet season in Ibadan lasts from March to
October. The city's dry season lasts from November to February. Ibadan's average total rainfall is 1420 $\mathrm{mm}$, occurring over 109 days. The average maximum temperature is $26.5^{\circ} \mathrm{C}$, the lowest temperature is $21.4^{\circ} \mathrm{C}$, and the relative humidity is $74.5 \%$. Economy activities in Ibadan include agriculture, commerce, handcrafts, manufacturing and service industries. There are a number of poultry farm settlement scattered across Ibadan especially at Akufo and Lalupon. Ibadan is rich with cheap sources of land and labour and are close to the commercial capital of the country, Lagos.

\section{Sample collection}

$5 \mathrm{mls}$ of blood samples were collected randomly from the jugular vein of commercial layer chicken (Isa brown) aged between 8 and 35 weeks with intensive and semi-intensive management from selected local government areas in Ibadan. Flock sizes ranged from 1500 to 3,000 birds, with most of the flocks containing 2000 to 2500 chickens. The chickens used for this study have no records of vaccination against Mycoplasma gallisepticum. The blood samples collected into sample bottles were allowed to stand in a slanting position for about 3 hours to allow for the separation of the serum from the cellular components of the blood. The serum was decanted in centrifuge tube and centrifuge at 2000rpm for 5 minutes to have a clear serum.

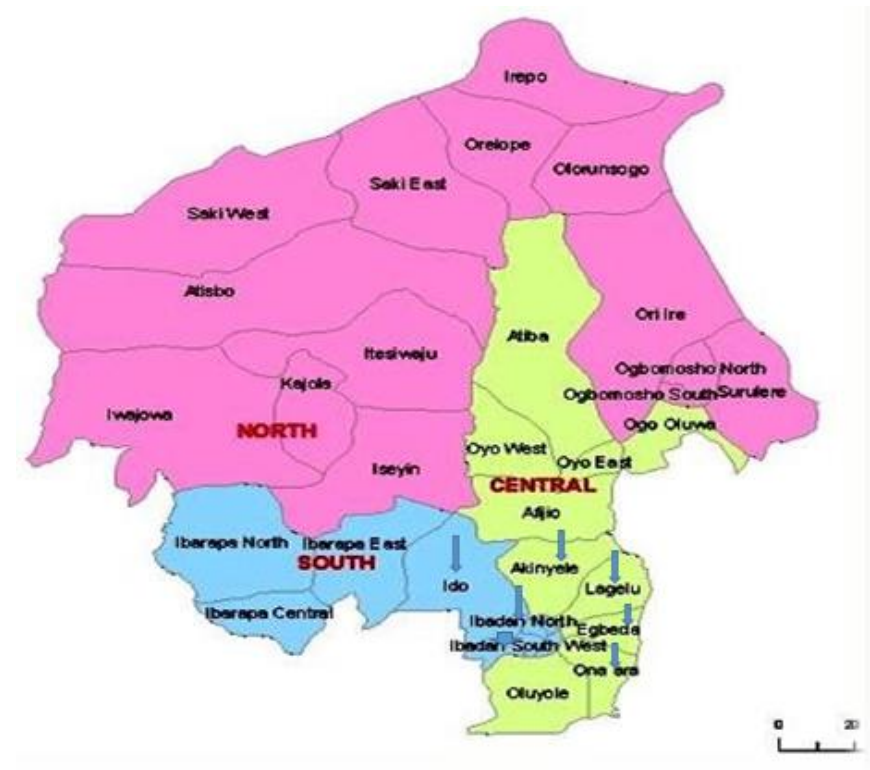

Figure 1: Map of Ibadan showing the study areas (Adefisan et al., 2015) 
The serum was then collected in another labelled sample bottles and then transported with ice packs to the $\mathrm{CHI}$ laboratory, Challenge, Ibadan for preservation at $-20^{\circ} \mathrm{C}$ until further processing for the serological study.

Indirect Enzyme Linked Immunosorbent Assay (ELISA) test was conducted to detect the antibodies against MG using (ProFLOK ${ }^{\mathrm{TM}}$ MG Ab, Manufactured by Zoetis inc, Kalamazoo, MI 49007, USA).

Based on the manual of the ELISA kit, the test is validated if: The normal control average optical density (OD) is less than 0.200 and the corrective positive control (CPC) is between 0.250 and 0.900 . When S/P ratio value is $\geq 0.6$ and antibody titre $\geq 744$, the S/P ratio and antibody titer are calculated as follows:

$S / P=($ Sample OD) - (Average normal control OD) Corrected positive control

MG ELISA titer

$\log _{10}$ (Titer) $=\left(1.464 \times \mathrm{LOG}_{10} \mathrm{~S} / \mathrm{P}\right)+3.197$

Titer $=$ Antilog of $\log _{10}$ Titer

\section{Data Analysis}

Tables were used to present all of the information gathered during the research. To see if there was a statistical difference in the disease prevalence rate, Chi-square test was conducted with SPSS version 20. At the $95 \%$ confidence interval, $\mathrm{P}<0.05$ values were considered significant.

The prevalence rate was calculated using the formula:

Prevalence $=\underline{\text { Positive samples } \times 100}$

Total samples analyzed

\section{Results}

The seroprevalence of MG antibody in commercial layer farms at different ages in the local government areas of Ibadan, Oyo state was studied by Enzyme linked Immunosorbent Assay (ELISA). Out of the 140 sera samples collected and analyzed, only 104 sera samples were positive, this shows $74.3 \%$ with prevalence of $60 \%, 70 \%, 75 \%, 80 \%, 85 \%, 75 \%$, and $75 \%$ for Abol farm, Rehoboth farm, Cornerstone farm, Agboola farm, Deborah farm, Brian farm and Betty farm respectively.

However, the overall results of prevalence of MG antibody shown in table 1, depicts details of 7 farms from where blood samples were collected.

Table 2 showed the prevalence of MG antibody was highest in $18-21$ weeks with $85 \%$, followed by $22-25$ weeks with $80 \%$ and lowest in $8-11$ weeks with $60 \%$.
Table 3 shows no seroprevalence in relation to flock size with 500-1800 group having 75\%, 1900-2200 group also having $75 \%$ and group $2300-2700$ having $70 \%$.

\section{Discussion}

In commercial layers in Ibadan, the overall seroprevalence of Mycoplasma gallisepticum (MG) infection was $74.3 \%$. This indicates that Mycoplasma gallisepticum is endemic in commercial layer chicken in Ibadan. Similar findings were reported by Ahmed et al. (2008) and Mera \& Mudashir (2019) who reported high seroprevalence of $91.83 \%$ and $88 \%$ in layer chicken in Niger and Sokoto state respectively. Other researchers (Ahmad, 2000; Wieliczko et al., 2000) have also recorded high seroprevalence in Pakistan and Poland. However, in contrast to this, Feizi et al. (2013) reported a lower prevalence of $33.3 \%$ in northwest of Iran.

The highest prevalence of MG infection was found to be $85 \%$ in the $18-21$ week age group, followed by $80 \%$ in the 22-25 week age group, and $60 \%$ in the $8-11$ week age group. This study denoted that older birds were more affected than younger birds. These findings are totally different from the reports of Sarkar et al. (2005) and Hossain et al. (2010) who reported a maximum prevalence of $71.6 \%$ at $16-23$ and 18-20 weeks of age, and the lowest seroprevalence of MG antibodies of $50.4 \%$ at 64 and 55 weeks of age. However, in contrast to this study, Ahmad, (2008) recorded maximum prevalence rate of MG infection with $74.60 \%$ in flocks aged 6 to 23 weeks, and the lowest prevalence rate was $33.17 \%$ in flocks aged 60-76 weeks.

The size of the flock has little effect on the serological findings. This study contradicts the work of Heleli et al. (2012), who reported $76.97 \%$ MG infection in a farm of 18000 birds in Algeria, compared to $20 \%$ in a flock of 500-1000 birds. Furthermore, Hossain et al. (2010) also reported that in Rajshahi and nearby regions of Bangladesh, the MG infection rate was higher $(68.25 \%)$ in large flocks compared to small flocks (50.1\%). Despite the fact that the majority of farms in the research area have small flocks and open shed poultry farms with poor management conditions, a smaller number of farms had satisfactory or good management. Other factors that may contribute to the high incidence in Ibadan include multiage production practice (where different age of flocks are kept together in the same farm), the building of chicken farms in the area and the ability of the microbes to persist longer in the area as well as a lack of basic bio-security measures. 
Table 1: Seroprevalence of Mycoplasma gallisepticum antibody by ELISA

\begin{tabular}{llllll}
\hline No. of farm & Age (wks) & No. of sera tested & No. of positive samples (\%) & Mean titer & CV (\%) \\
\hline Abol & 8 & 20 & $12(60)$ & 1126 & 69.56 \\
Rehoboth & 15 & 20 & $14(70)$ & 1100 & 66.20 \\
Cornerstone & 12 & 20 & $15(75)$ & 1115 & 60.56 \\
Agboola & 25 & 20 & $16(80)$ & 900 & 60.32 \\
Deborah & 20 & 20 & $17(85)$ & 1250 & 65.32 \\
Brain & 33 & 20 & $15(75)$ & 1115 & 61.56 \\
Betty & 27 & 20 & $15(75)$ & 800 & 58.66 \\
\hline
\end{tabular}

Table 2: Seroprevalence of Mycoplasma gallisepticum (MG) antibody by age

\begin{tabular}{lllll}
\hline Age of birds (weeks) & No. of sera tested & No. of positive samples & Prevalence (\%) & $P$-value \\
\hline $8-11$ & 20 & 12 & 60 & $0.062 *$ \\
$12-15$ & 40 & 29 & 72 & \\
$18-21$ & 20 & 17 & 85 & \\
$22-25$ & 20 & 16 & 80 & \\
$26-29$ & 20 & 15 & 75 & \\
$30-33$ & 20 & 15 & 75 & \\
\hline
\end{tabular}

*Significant $(p<0.05)$

Table 3: Seroprevalence of MG antibody in relation to flock size

\begin{tabular}{lllll}
\hline Flock size (No. of birds/flock) & No. of sera tested & No. of positive samples & Prevalence (\%) & $P$-value \\
\hline $1500-1800$ & 40 & 30 & 75 & $0.777^{\text {NS }}$ \\
$1900-22001$ & 40 & 30 & 75 & 70 \\
$2300-2600$ & 20 & 14 & 75 & \\
$2700-3000$ & 40 & 30 & & \\
\hline
\end{tabular}

NS-Not significant at $\mathrm{p}<0.05, \mathrm{MG}=$ Mycoplasma gallisepticum

However, it has also been noted that the MG infection are more severe than previously thought.

According to the findings of this study, MG is endemic in layer chicken flocks in Ibadan, Nigeria. Efforts should be focused on educating poultry producers on how to effectively control MG in layer farms through proper management and the use of appropriate preventive or therapeutic methods. Furthermore, a more in-depth investigation of the prevalence and characteristics of MG across the country should be conducted to determine the disease's present state in Nigeria. In addition, the role of vaccination should be investigated in order to avoid unjustified antibiotic use in the treatment of infection.

\section{Acknowledgement}

The author is grateful to Dr Bankole Olorunsola from the Veterinary Zoetis/ Alpha in conjunction with $\mathrm{CHI}$ Laboratory, Ibadan for the Laboratory analysis of this study. Also the participating farmers for their support during the experimentation.

\section{Conflict of interest}

The authors declare that there is no conflict of interest.

\section{References}

Adefisan EA, Bayo AS \& Ropo OI (2015). Application of geo-spatial technology in identifying areas vulnerable to flooding in Ibadan metropolis. Journal of Environment Earth Science, 5(14): 153-66.

Ahmad A, Rabbani M, Yaqoop T, Ahmad A, Shabbir $M Z$ \& Akhtar F (2008). Status of IgG antibodies against Mycoplasma gallisepticum in non-vaccinated commercial poultry breeder flocks. Journal of Animal Plant Science, 18(2-3): 61-63.

Ahmed JS, Lawal SM, Fatihu MY, Moses DG, Barde IJ, Kumbish PR \& Oladele SB (2015). Isolation and serological detection of Mycoplasma gallisepticum and Mycoplasma synoviae using a combined MG/MS enzyme-linked immunosorbent assay kit in indigenous chickens in Niger State, Nigeria. African Journal of Cellular Pathology, 30; 4(6): 70-3. 
Buim MR, Mettifogo E, Timenetsky J, Kleven S \& Ferreira AJP (2009). Epidemiological survey on Mycoplasma gallisepticum and Mycoplasma synoviae by multiplex PCR in commercial poultry. Pesquisa Veterinaria Brasileira, 29(7): 552- 556.

Feizi A, Bijanzad P, Khakpour M, Nikpiran H, Kaboli K \& Moggadam ARJ (2013). Seroprevalence of Mycoplasma gallisepticum infection in Iranian northwest broiler breeder farms. Annals of Biological Research, 4(4): 109-1

Hossain KMM, Ali MY \& Haque MI (2007). Seroprevalence of Mycoplasma gallisepticum infection in chicken in the greater Rajshahi District of Bangladesh. Bangladesh. Journal of Veterinary Medicine, 5(1 \& 2): 9-14.

Hossain KMM, Hossain MDT \& Yamato I (2010). Seroprevalence of Salmonella and Mycoplasma gallisepticum Infection in Chickens in Rajshahi and Surrounding Districts of Bangladesh. International Journal of Biology, 2(2): 74-80.

Heleili N, Ayachi A, Mamache B \& Chelihi AJ (2012). Seroprevalence of Mycoplasma synoviae and Mycoplasma gallisepticum at Batna Commercial poultry farms in Algeria. Veterinary World, 5(12): 709-712.

Ley DH \& Yoder HW Jr (1997). Mycoplasma gallisepticum infection. In: Disease of
Poultry, tenth edition. Calnek BW, Barnes HJ, Beard CW, McDougald LR, Saif YM, Eds. Iowa State University Press, Ames, Iowa. USA. Pp 194-207.

Mera UM \& Mudasir H (2019). Prevalence of Mycoplasma galisepticum (MG) antibodies in chicken in Sokoto, Nigeria. EAS Journal of Veterinary Medical Services, 1(5): 58-9.

Osman KM, Aly MM, Amin ZMS \& Hassan BS (2009). Mycoplasma gallisepticum: an emerging challenge to the poultry industry in Egypt. Revue Scientifique et Technique (Office International Epizootic), 28(3): 1015-1023.

Sarkar SK, Rahman MB, Rahman M, Amin KMR, Khan MFR \& Rahman MM (2005). Sero-Prevalence of Mycoplasma gallisepticum Infection of Chickens in Model Breeder Poultry Farms of Bangladesh. International Journal of Poultry Science, 4(1): 32-35. 17.

Silva RF, Elmiro RN, Virginia LAP, Maria LB \& Maria GFN (2008). Mycoplasma synoviae infection on Newcastle disease vaccination of chickens. Brazil Journal of Microbiology, 39(2): 384-389.

Wieliczko A, Mazurkiewicz M, Wiśniewska J (2000). Infections with Mycoplasma gallisepticum/synoviae in serological examination. Medycyna Weterynaryjna, 56(4): 240-244. 